\title{
Efficacy of Viola odorata flower decoction in chronic rhinosinusitis
}

\author{
Imamuddin MULLA', Mariyam ROQAIYA ${ }^{2}$, Mohd Imran KHAN ${ }^{3}$ \\ ${ }^{1}$ Department of Moalajat, Luqman Unani Medical College Hospital and Research Centre Bijapur, Karnataka, India \\ ${ }^{2}$ Department Niswan Wa Qabala, Luqman Unani Medical College Hospital and Research Centre Bijapur, Karnataka, India \\ ${ }^{3}$ Department of Pharmacology, National Institute of Unani Medicine Bengaluru, Karnataka, India \\ Correspondence \\ Mariyam ROQAIYA \\ Department of Niswan Wa Qabala, Luqman Unani Medical College Hospital and Research Centre Bijapur, Karnataka, India \\ e-mail:dr.mroqaiya@gmail.com
}

\begin{abstract}
Chronic rhinosinusitis (CRS) is one of the most frequent otorhinolaryngologic diseases encountered in daily practice with an estimated prevalence of $14 \%$ of the global population. This study aimed to explore the efficacy of Viola odorata flower decoction against CRS.

In this prospective randomized controlled trial, 30 patients with CRS were randomly assigned to receive either test drug (10 $\mathrm{g}$ of $\mathrm{V}$. odorata flower in the form of decoction administered orally empty stomach in the morning daily) or active control drug (single nasal spray of fluticasone propionate $50 \mu \mathrm{g} / \mathrm{spray}$ in each nostril daily) for 30 days. The primary outcome measure was an improvement in sinonasal symptoms assessed using a 22-item sinonasal outcome questionnaire (SNOT-22). Reduction in absolute eosinophil count (AEC) and improvement in X-ray paranasal sinus were secondary outcome measures. The significance level was kept as $5 \%$.

After completing the therapy, the SNOT-22 score was significantly low in the test group compared with the control group and a significant difference was found in AEC between the groups. Also, the SNOT-22 score remained significantly low after completion of the treatment on the 45th and 60th days compared with the control drug. Changes in $\mathrm{x}$-ray paranasal sinuses were not significant between the groups. These results suggested that $V$. odorata flower was effective in reducing the symptoms of CRS.

Trial Registration No. Clinical Trial Registry of India CTRI/2017/09/009788 (01/09/2016)
\end{abstract}

Key words: Flower; herbal medicine; quality of life; sinonasal; Viola odorata

\section{INTRODUCTION}

Rhinosinusitis is a group of disorders characterized by inflammation of the nasal mucosa and the mucosa of the paranasal sinuses [1]. The inflammation of the nasal and sinus mucosa often coexists in this condition, and hence the term "rhinosinusitis" has been given [2]. Rhinosinusitis is considered as chronic when symptomatic inflammation of the nasal and sinus mucosa persists for more than $>12$ weeks, with or without exacerbations [1-4]. Chronic rhinosinusitis (CRS) is one of the most frequent otorhinolaryngologic diseases encountered in daily practice [3] with an estimated prevalence of $14 \%$ of the global population [5].

In the medical management of CRS, topical administration of corticosteroids is considered as the first-line therapy. Nasal irritation, mucosal bleeding, and crusting have been found to be associated with the daily use of topical nasal steroids. Further long-term systemic steroid use is associated with significant side effects
[1]. Surgery is usually considered as a last option for patients not responding to medical management. Recurrence has been noted with surgical treatment and is often not successful. Therefore, no effective medical or surgical treatment is available to provide complete cure for CRS. So, alternative therapeutic strategies need to be explored for the same [6].

Viola odorata, popularly known as "Banafsha" in Asia [7] and frequently recognized as wood violet, sweet violet, English violet, common violet, florist's violet, or garden violet [7-10], is cultivated and grows spontaneously on six continents with Mediterranean and temperate climates [11]. In India, it is distributed in Kashmir, Western Himalayan region, at an altitude of 1500-1800 $m$ [12]. According to Unani literature, Viola odorata flowers (gulebanafsha) possess anti-inflammatory, analgesic, blood-purifying, and expectorant properties $[13,14]$. It is a remedy for respiratory problems such as bronchitis, 
cough, and asthma $[13,15]$. Several experimental studies have been conducted showing its anti-inflammatory, antimicrobial, sedative, and pre-anesthetic properties. In clinical studies, the adjuvant use of violet syrup with short-acting $\beta$-agonist was found to enhance cough suppression in children with intermittent asthma [16]. Also, the frequencies of tonsillitis and peritonsillar abscess reduced with the administration of decoction of $V$. odorata flowers [17]. The objective of this study was to investigate the effect of $V$. odorata flowers in reducing the symptoms of CRS.

\section{METHODOLOGY}

\section{Study design}

This randomized controlled trial was conducted in the Department of Moalajat, Luqman Unani Medical College (LUMC) Hospital and Research Center, Vijaypur, Karnataka, from November 2016 to March 2018 conforming to the tenets of the Declaration of Helsinki. The study protocol was approved by the Institutional Ethical Committee (IEC), LUMC, Vijaypur, under.IEC No: BJP/LUMC/PG/IEC/2015-16/01/MOALAJAT/02. The trial was registered by the Clinical trial Registry of India with registration number CTRI/2017/09/009788. All patients were required to sign a consent form before participating in the trial.

\section{Sample size estimation}

The sample size of this study was calculated by taking assumptions needed to demonstrate a difference by a new treatment in terms of costs and risks: assumed effect size of 9 and assumed standard deviation of 8.44 . Based on these assumptions, a sample containing 28 participants, 14 in each group, was found to be sufficient to rule out a clinically important difference of 9 between the 2 groups in reducing 22-item sinonasal outcome questionnaire (SNOT-22) score, assuming a standard deviation of 8.44 and using a two-tailed $t$ test of the difference between means with $80 \%$ power and a $5 \%$ level of significance. After considering $10 \%$ as a dropout rate, the sample size required was approximately 30 (15 in each group).

\section{Participant selection and criteria}

The male and female patients aged 18-50 years fulfilled the diagnostic criteria for CRS of the American Academy of Otolaryngology-Head and Neck Surgery. According to this criteria, a patient was diagnosed with CRS if 12 weeks or longer of two or more of signs and symptoms of mucopurulent drainage, nasal obstruction, facial pain/pressure/fullness, or reduced sense of smell were observed, besides inflammation documented by one or more of the findings of purulent mucus or edema in the middle meatus or anterior ethmoid region, polyps in the nasal cavity or the middle meatus, and/or radiographic imaging showing inflammation of the paranasal sinuses. Patients were excluded if they had known systemic and metabolic diseases, external injuries, nasal polyps, and nasal growth. Pregnant and lactating women were also excluded. Patients were randomized as 1:1 into the test or control group, 15 patients in each group, using an open list of random numbers produced from an online randomization list generator (www.randomization.com). The sequence of random numbers was concealed from the researcher collecting the data until the interventions were assigned to each patient.

\section{Intervention}

The gule banafsha ( $V$. odorata flower) was purchased from a local drug market of Vijaypur city and identified and authenticated by Professor Syed Saleemuddin Ahmed, Department of Pharmacology. The voucher specimen has been stored in the laboratory of the Department of Pharmacology, LUMC Hospital and Research Center, Vijayapur, Karnataka. Small sachets were made, each containing $10 \mathrm{~g}$ dried gule banafsha. Patients were instructed to prepare a decoction by adding each sachet in $250 \mathrm{~mL}$ of water, followed by boiling it for $5 \mathrm{~min}$, sieving it, and use it empty stomach in the morning daily for 30 days. In the control group, a single nasal spray of fluticasone propionate ( $50 \mu \mathrm{g} / \mathrm{spray})$ in each nostril in the morning daily was given for 30 days. Compliance was assessed at every follow-up by examining the lock bags in which the medication was dispensed at the previous visit.

\section{Study procedure}

During the first visit, a detailed history, including the onset and duration of nasal blockage, running nose, sneezing, facial pain, decreased sense of smell, ear pain, ear fullness, history of allergy, and any previous treatment, was taken, and a complete physical examination was done. Systemic examination of Central Nervous System (CNS), Cardiovascular System (CVS), and Respiratory System (RS), and abdominal examination was performed in each patient. Following the evaluation, the patients were advised to go for necessary investigations, including absolute eosinophil count (AEC) and x-ray (Water's view). Serum Glutamic-Ocaloacetic Transaminase (SGOT), Serum Glutamic Pyruvic Transaminase 
(SGPT), blood urea, and serum creatinine levels were also determined to assess the safety of the drug. Patients meeting the inclusion criteria were provided an information sheet containing details regarding the nature of the study. Patients were given enough time and opportunity to read and understand the details of the study mentioned in the information sheet and ask any questions. They were given the right to deny or withdraw the treatment during any part of the study without sharing any reason. After obtaining the willingness, they were asked to take part in the study and sign the consent form. The patients were followed up on the 15th and 30th days during the treatment. The sinonasal symptoms were assessed on each visit using the SNOT-22 score. AEC and $x$-ray of the paranasal sinuses were repeated after completion of the treatment. Two follow-ups were done on the 45th and 60th days to see the recurrence of symptoms and persistence of the therapeutic effect of the drugs by assessing the SNOT22 score. Inquiries regarding any side effects were made and documented properly. Reduction in the SNOT 22 score was used as the primary outcome measure, while a reduction in AEC and improvement in x-ray paranasal sinuses (PNS)findings were analyzed as secondary outcome measures. Changes in maxillary sinus opacity, frontal sinus opacity, and ethmoidal sinus opacity in patients with rhinosinusitis were assessed and graded arbitrarily as severe, moderate, mild, and nil.

\section{SNOT-22}

SNOT-22 is a questionnaire related to a sinonasal symptom, which is extensively used in the literature to assess the quality of life in sinonasal diseases. It assesses nasal, paranasal, and psychological symptoms, and also symptoms associated with sleep [8].

\section{Statistical analysis}

The results on categorical variables were presented as number (\%), while continuous variables were presented as mean \pm standard deviation (SD) (min-max). The level of significance was kept at 5\%. To analyze the significance of study parameters on a continuous scale, Student t test (two tailed, independent) and Student $t$ test (two tailed, dependent) were used for inter- and intragroup analyses, respectively. To analyze the significance of study parameters on categorical scale between two or more groups, the chi-square/Fisher Exact test was used. The statistical software used for the analysis of data were SPSS 18.0 and R environment ver.3.2.2. Microsoft Word and Excel were used to generate graphs and tables.

\section{RESULTS}

\section{Participant selection}

A total of 151 patients were screened; 19 patients denied to participate in the study, and 132 were subjected to investigation. Of these, 102 patients were excluded from the study and 30 patients were randomly allocated (Figure 1).

\section{Baseline characteristics}

At baseline, patients were assessed for different variables such as age sex, diet, occupation, and socioeconomic condition. Both groups were found to be statistically similar (Table 1).

\section{Primary outcome}

The baseline SNOT-22 score was not significantly different between the two groups with a $P$ value of 0.08 . In the test group, the mean of the SNOT-22 score was reduced from $62.53 \pm 5.21$ to $41.87 \pm 4.41$ and $14.07 \pm 8.64$ after 15-day and 30-day treatment with a mean difference of 20.667 and 48.467 , respectively. After treatment, the score remained low from the baseline with a mean difference of 52.533 and 51.267 on the 45th day and 60th day, respectively. These changes in the SNOT-22 score within the group were statistically significant with a $P$ value $<0.001$. When changes in the SNOT-22 in the test group were compared with those in the control group, a statistically significant difference was observed in the SNOT-22 score on the 15 th, 45th, and 60th days between the groups, showing the long-term efficacy of the test drug (Table 2).

\section{Secondary outcome measures}

As shown in Table 2, after a 1-month treatment, the mean score of eosinophil count was reduced from 823.33 cells $/ \mathrm{mm}^{3}$ to 360.00 cells $/ \mathrm{mm}^{3}$ with a mean difference of 463.333 in the test group, which was statistically significant with a $P$ value $<0.001$. When the test group was compared with the control group statistically using the unpaired t test, after completion of treatment, a significant difference was found between the two groups with a $P$ value $<0.001$, where the test drug decreased eosinophil count more prominently compared with the control drug.

Changes in maxillary sinus opacity, frontal sinus opacity, and ethmoidal sinus opacity in patients with rhinosinusitis were assessed and arbitrary graded as severe, moderate, mild, and nil. In the test group, sinus opacity was resolved completely after 30 days of treatment in four patients and partially in six patients; PNS opacity was reduced from grades severe and moderate 


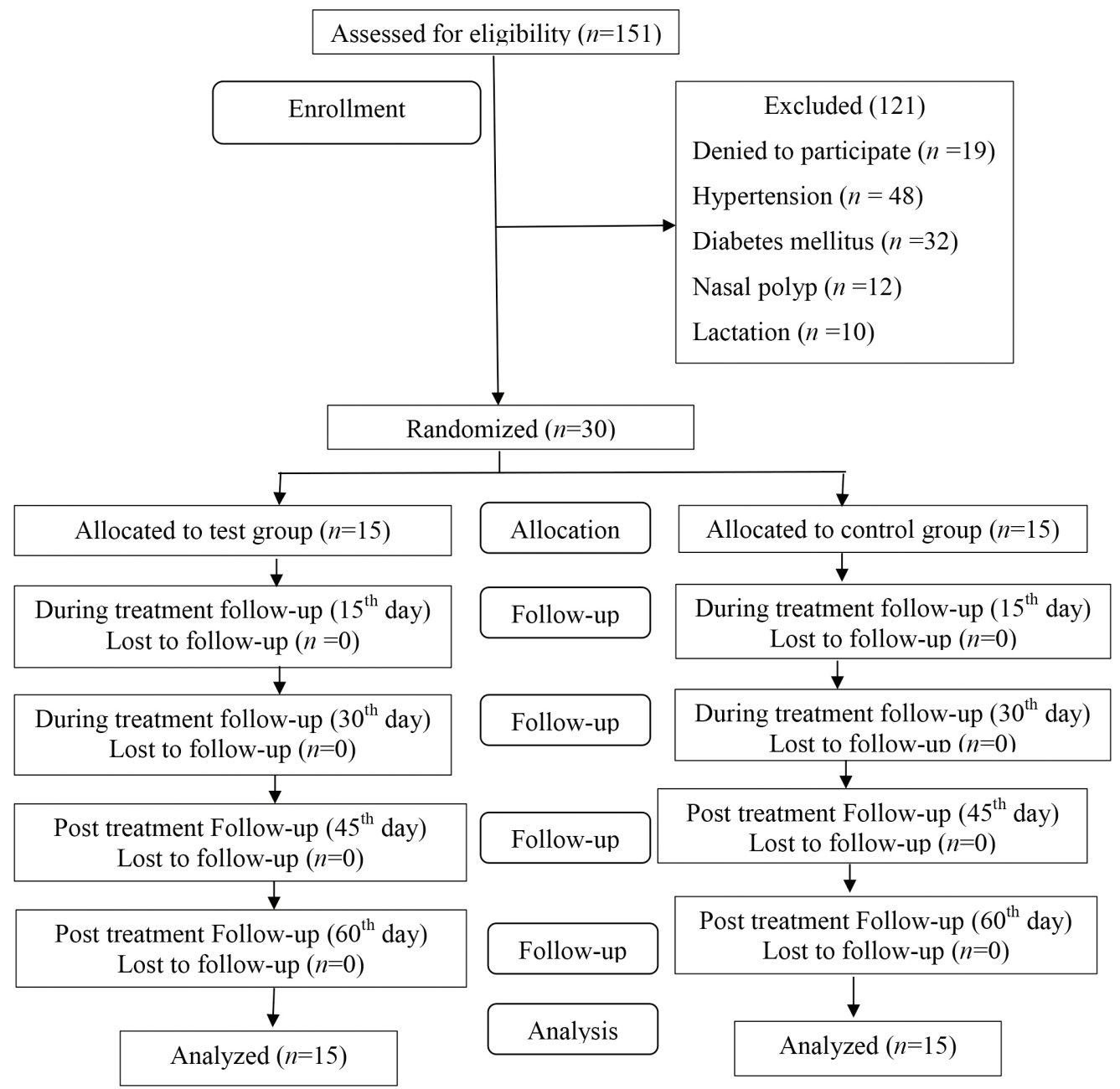

Figure 1 Flow chart as per the CONSORT statement.

to mild with a percentage change of $40 \%$. However, in the control group, no patient was relieved completely; however, three patients were relieved partially as PNS opacity was reduced from grades severe and moderate to mild with a percentage change of $20 \%$. When these observations were compared between the two groups, no significant difference was found with a $P$ value of 0.123 . In the test group, after completion of the treatment, frontal sinus opacity was resolved completely in four patients with a percentage change of $26.7 \%$. However, in the control group, no patient was relieved completely or partially. When these observations were compared between the two groups, a significant difference was found with a $P$ value of 0.042 . In the test group, after completion of the treatment, two patients were relieved partially because PNS opacity was reduced from grades severe and moderate to mild with a percentage change of $13.3 \%$. However, in the control group, two patients were relieved completely after the treatment with a percentage change of $13.3 \%$. When these observations were compared between the two groups, no significant difference was found with a $P$ value of 0.483 (Table 4).

\section{DISCUSSION}

The results of this study showed that both test and control drugs significantly reduced the SNOT-22 score after a 1-month treatment. CRS is considered as a multifactorial disease characterized by a variety of disorders leading to inflammation of nasal and sinus mucosa. It may also include bacterial, viral, fungal, allergic, nonallergic, inflammatory, pharmacologic, neural, genetic, and hormonal causes (18-20). An ionone-like compound known as 3-acrylic acid from the aerial parts of $V$. odorata at $6 \mathrm{mg} /$ disk concentration showed significant antibacterial efficacy against 
Table 1 Demographic profile of the patients in the test and control groups

\begin{tabular}{|c|c|c|c|}
\hline Basic variables & $\begin{array}{l}\text { Test group } \\
(n=15)\end{array}$ & $\begin{array}{l}\text { Control group } \\
(n=15)\end{array}$ & aP value \\
\hline \multicolumn{4}{|l|}{ Age (year) } \\
\hline $20-30$ & $6(40 \%)$ & $8(53.3 \%)$ & \multirow[t]{4}{*}{0.087} \\
\hline $31-40$ & $8(53.3 \%)$ & $7(46.7 \%)$ & \\
\hline $41-50$ & $1(6.7 \%)$ & $0(0 \%)$ & \\
\hline Mean \pm SD & $32.80 \pm 5.80$ & $29.07 \pm 5.73$ & \\
\hline \multicolumn{4}{|l|}{ Sex } \\
\hline Female & $1(6.7 \%)$ & $3(20 \%)$ & \multirow[t]{2}{*}{0.598} \\
\hline Male & $14(93.3 \%)$ & $12(80 \%)$ & \\
\hline \multicolumn{4}{|l|}{ Occupation } \\
\hline Business & $5(33.3 \%)$ & $2(13.3 \%)$ & \multirow[t]{6}{*}{0.672} \\
\hline Student & $3(20 \%)$ & $4(26.7 \%)$ & \\
\hline Unskilled worker & $3(20 \%)$ & $2(13.3 \%)$ & \\
\hline Professional & $1(6.7 \%)$ & $4(26.7 \%)$ & \\
\hline Skilled worker & $2(13.3 \%)$ & $2(13.3 \%)$ & \\
\hline Housewife & $1(6.7 \%)$ & $1(6.7 \%)$ & \\
\hline \multicolumn{4}{|l|}{ Diet } \\
\hline Mixed & $12(80 \%)$ & $12(80 \%)$ & \multirow[t]{2}{*}{1} \\
\hline Vegetarian & $3(20 \%)$ & $3(20 \%)$ & \\
\hline \multicolumn{4}{|c|}{ Socioeconomic status } \\
\hline Upper class & $4(26.7 \%)$ & $5(33.3 \%)$ & \multirow[t]{5}{*}{1} \\
\hline Upper middle class & $8(53.3 \%)$ & $7(46.7 \%)$ & \\
\hline Lower middle class & $2(13.3 \%)$ & $3(20 \%)$ & \\
\hline Upper lower class & $1(6.7 \%)$ & $0(0 \%)$ & \\
\hline Lower class & $0(0 \%)$ & $0(0 \%)$ & \\
\hline \multicolumn{4}{|c|}{ Duration of illness (month) } \\
\hline$<12$ & $3(20 \%)$ & $6(40 \%)$ & \multirow[t]{4}{*}{0.823} \\
\hline $12-24$ & $12(80 \%)$ & $8(53.3 \%)$ & \\
\hline$>24$ & $0(0 \%)$ & $1(6.7 \%)$ & \\
\hline Mean \pm SD & $14.27 \pm 4.57$ & $14.80 \pm 7.91$ & \\
\hline
\end{tabular}

${ }^{a}$ Chi square test/Fisher exact test

selected respiratory bacteria (9). V. odorata has been found to be active against different bacterial species in several animal studies $(21,22-25)$. The antimicrobial effect of $V$. odorata was found to be high in flowers compared with leaves and roots (25). Prophylactic administration of the $V$. odorata extract was found to be partially effective in preventing lung damage, while it was found to be equally effective in hydrocortisone in aiding the resolution of formalin-induced lung damage (26). In vivo, the injections of different dosages of the ethanolic and chloroform extracts of $V$. odorata were found to increase sleeping time and also showed better sedation and pre-anesthetic effects in a dosedependent manner compared with diazepam (27). The aqueous extract of the aerial parts of $V$. odorata showed significant diuretic activity (28). Clinically the adjuvant administration of $V$. odorata syrup along with short-acting $\beta$-agonist showed cough suppression in children with intermittent asthma (16). Frequencies of tonsillitis and peritonsillar abscess were reduced with administration of the decoction of $V$. odorata flowers (17). Nasal drops of $V$. odorata were found to be efficacious in patients of insomnia because they showed significant improvements in sleep and insomnia severity index scores after a 1-month treatment (29). The SNOT-22 questionnaire comprised several parameters, including cough, nasal blockage, ear fullness, ear pain, facial pain, sleep disturbances, sneezing, and running nose. Thus, the reduction in the SNOT-22 score could be explained on the basis of the aforementioned effects of $V$. odorata in animal studies as well as clinical trials.

Eosinophils are considered to play a major role in the pathogenesis of eosinophilic CRS through the release of noxious secretary granules. They also cause the release of major basic proteins, eosinophil-derived neurotoxins, eicosanoids, and various cytokines. The eosinophils histologically infiltrate into the epithelium out to the sinus cavity through the thickened basement membrane. Continuous eosinophilic inflammation causes the disruption of mucociliary clearance systems resulting in impaired immune capabilities and raises the possibility of infectious damage to the host (30). Sreeparvathi et al. demonstrated a significant correlation between eosinophil counts in tissues and blood with increased severity of symptoms in patients suffering from eosinophilic CRS with nasal polyps in the Indian population (31). Prophylactic administration of the $V$. odorata extract was found to be partially effective in preventing lung damage, while it was found to be equally effective to hydrocortisone in aiding the resolution of formalin-induced lung damage (26). Generally, eosinophilic CRS is related to steroid responsiveness (32). Dahl et al did not observe any effect of the administration of nasal corticosteroids for 6 weeks on airway reactivity or induced sputum eosinophilia (33). Lee et al observed that the $V$. odorata extract caused considerable inhibition of the effect of the total serum level of IgE and cytokines IL-3 and IL-4 on the inflammation of respiratory tracts in allergic mice. It also effectively reduced the overactivity of the airways, eosinophilia, and excessive secretion of mucus (16). 
Table 2 Comparison of SNOT 22 score in the two groups of the patients studied

\begin{tabular}{|l|l|l|l|l|}
\hline SNOT 22 & Test group & Control group & Total & P value \\
\hline Before treatment & $62.53 \pm 5.21$ & $59.27 \pm 4.62$ & $60.90 \pm 5.11$ & 0.080 \\
\hline 15th day & $41.87 \pm 4.41$ & $29.73 \pm 4.22$ & $35.80 \pm 7.49$ & $<0.001 a^{* *}$ \\
\hline 30th day & $14.07 \pm 8.64$ & $18.87 \pm 5.51$ & $16.47 \pm 7.53$ & 0.080 \\
\hline 45th day & $10.00 \pm 7.56$ & $17.80 \pm 7.22$ & $13.90 \pm 8.28$ & $0.007 \mathrm{a}^{* *}$ \\
\hline 60th day & $11.27 \pm 7.39$ & $23.87 \pm 7.07$ & $17.57 \pm 9.57$ & $<0.001 \mathrm{a}^{* *}$ \\
\hline Difference from BT & \multicolumn{5}{|l|}{} \\
\hline 15th day & 20.667 & 29.533 & 25.100 & - \\
\hline 30th day & 48.467 & 40.400 & 44.433 & - \\
\hline 45th day & 52.533 & 41.467 & 47.000 & - \\
\hline 60th day & 51.267 & 35.400 & 43.333 & - \\
\hline P value from BT & \multicolumn{5}{|l|}{} \\
\hline 15th day & $<0.001 \mathrm{~b}^{* *}$ & $<0.001 \mathrm{~b}^{* *}$ & $<0.001 \mathrm{~b}^{* *}$ & - \\
\hline 30th day & $<0.001 \mathrm{~b}^{* *}$ & $<0.001 \mathrm{~b}^{* *}$ & $<0.001 \mathrm{~b}^{* *}$ & - \\
\hline 45th day & $<0.001 \mathrm{~b}^{* *}$ & $<0.001 \mathrm{~b}^{* *}$ & $<0.001 \mathrm{~b}^{* *}$ & - \\
\hline 60th day & $<0.001 \mathrm{~b}^{* *}$ & $<0.001 \mathrm{~b}^{* *}$ & $<0.001 \mathrm{~b}^{* *}$ & - \\
\hline
\end{tabular}

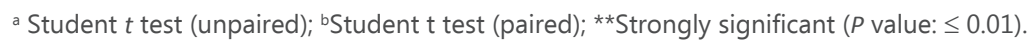

Table 3 Comparison of absolute eosinophil count (cells $/ \mathrm{mm}^{3}$ ) in the two groups of patients studied

\begin{tabular}{|l|l|l|l|}
\hline $\begin{array}{l}\text { Absolute eosinophil count (Cells/ } \\
\mathrm{mm}^{3} \text { ) }\end{array}$ & Test group & Control group & $P$ value \\
\hline Before treatment & $823.33 \pm 92.32$ & $766.67 \pm 97.59$ & 0.114 \\
\hline After treatment & $360.00 \pm 60.36$ & $486.67 \pm 91.55$ & $<0.001^{* * a}$ \\
\hline Difference & 463.333 & 280.000 & - \\
\hline P value & $<0.001^{* * \mathrm{~b}}$ & $<0.001^{* * \mathrm{~b}}$ & - \\
\hline
\end{tabular}

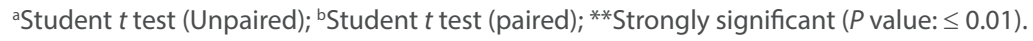

If history and physical examinations are equivocal, or if conventional treatment has failed, paranasal sinuses imaging is usually done to supports the clinical findings or confirm the diagnosis. Sinus ostial obstruction in sinonasal inflammatory disease is a very common cause of an opacified paranasal sinus (34). Water-soluble polysaccharides extracted from the grass of $V$. odorata possessed anti-inflammatory activity manifested by the suppression of the exudation and proliferation stages of inflammation (35). The safety profile was found to be within the normal limit in both the groups (Table 5). No adverse reactions were noted in both the groups. Also, in other clinical trials with $V$. odorata flowers, no adverse effects were noted $(16,17,29)$. Small sample size and long-term follow-up were the limitations of this study. Further studies are recommended with a large sample size along with long-term follow-up.

\section{CONCLUSIONS}

The test drug was found to be equally effective in reducing the SNOT-22 score compared with the control drug. Additionally, a statistically significant long-term effect of the test drug was noted. Regarding the changes in z-ray paranasal sinuses, both the test and control drugs were found to be equally effective. Therefore, it was inferred that the research drug controlled CRS.

Conflict of interest: None declared.

Funding Source: None declared.

\section{REFERENCES}

1. Suh JD, Kennedy DW. Treatment options for chronic rhinosinusitis. Proc Am ThoracSoc 2011; 8: 132-140. [PubMed] https://www.ncbi.nlm.nih.gov/pubmed/21364231

2. Crombruggen KV, Zhang N, Gaveart P, Tomassen P, Bachert C. Pathogenesis of chronic rhinosinusitis: Inflammation. J Allergy Clinlmmunol2011; 128(4): 728-732.[PubMed] https://www. ncbi.nlm.nih.gov/pubmed/21868076 
Table 4 Comparison of $x$-ray PNS opacity between the groups

\begin{tabular}{|c|c|c|c|}
\hline Maxillary sinus & Before treatment & After treatment & $\%$ change \\
\hline \multicolumn{4}{|l|}{ Test group $(n=15)$} \\
\hline No opacity & $0(0 \%)$ & $4(26.7 \%)$ & 26.70 \\
\hline Mild opacity & $2(13.3 \%)$ & $8(53.3 \%)$ & 40.00 \\
\hline Moderate opacity & $4(26.7 \%)$ & $3(20 \%)$ & -6.70 \\
\hline Severe opacity & $9(60 \%)$ & $0(0 \%)$ & -60.00 \\
\hline \multicolumn{4}{|c|}{ Control group $(n=15)$} \\
\hline No opacity & $3(20 \%)$ & $3(20 \%)$ & 0.00 \\
\hline Mild opacity & $0(0 \%)$ & $3(20 \%)$ & 20.00 \\
\hline Moderate opacity & $3(20 \%)$ & $7(46.7 \%)$ & 26.70 \\
\hline Severe opacity & $9(60 \%)$ & $2(13.3 \%)$ & -46.70 \\
\hline$P$ value & $0.204 a$ & $0.123 a$ & - \\
\hline \multicolumn{4}{|l|}{ Frontal grading } \\
\hline \multicolumn{4}{|l|}{ Test group $(n=15)$} \\
\hline No opacity & $11(73.3 \%)$ & $15(100 \%)$ & 26.70 \\
\hline Mild opacity & $1(6.7 \%)$ & $0(0 \%)$ & -6.70 \\
\hline Moderate opacity & $3(20 \%)$ & $0(0 \%)$ & -20.00 \\
\hline Severe opacity & $0(0 \%)$ & $0(0 \%)$ & 0.00 \\
\hline \multicolumn{4}{|c|}{ Control group $(n=15)$} \\
\hline No opacity & $10(66.7 \%)$ & $10(66.7 \%)$ & 0.00 \\
\hline Mild opacity & $0(0 \%)$ & $0(0 \%)$ & 0.00 \\
\hline Moderate opacity & $5(33.3 \%)$ & $5(33.3 \%)$ & 0.00 \\
\hline Severe opacity & $0(0 \%)$ & $0(0 \%)$ & 0.00 \\
\hline$P$ value & $0.682 \mathrm{a}$ & $0.042 a^{*}$ & - \\
\hline \multicolumn{4}{|l|}{ Ethmoidal grading } \\
\hline \multicolumn{4}{|l|}{ Test group $(n=15)$} \\
\hline No opacity & $13(86.7 \%)$ & $13(86.7 \%)$ & 0.00 \\
\hline Mild opacity & $0(0 \%)$ & $2(13.3 \%)$ & 13.30 \\
\hline Moderate opacity & $1(6.7 \%)$ & $0(0 \%)$ & -6.70 \\
\hline Severe opacity & $1(6.7 \%)$ & $0(0 \%)$ & 6.70 \\
\hline \multicolumn{4}{|c|}{ Control group $(n=15)$} \\
\hline No opacity & $12(80 \%)$ & $14(93.3 \%)$ & 13.30 \\
\hline Mild opacity & $0(0 \%)$ & $0(0 \%)$ & 0.00 \\
\hline Moderate opacity & $2(13.3 \%)$ & $1(6.7 \%)$ & -6.60 \\
\hline Severe opacity & $1(6.7 \%)$ & $0(0 \%)$ & -6.7 \\
\hline$P$ value & $1 \mathrm{a}$ & $0.483 a$ & - \\
\hline
\end{tabular}

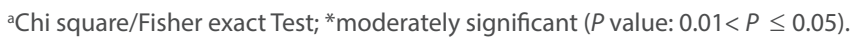

3. Deepti NV, Menon UK, Madhumita K. Chronic Rhinusinusitis-An Overview. Amrita Journal of Medicine 2012; 8(1): 4-9

4. Hashemian F, Baghbanian N, Majd Z, Rouini MR, Jahanshahi J, Hashemian F. Eur Arch Otorhinolaryngol2015; 272(6): 1429-1435.[PubMed] https://www.ncbi.nlm.nih.gov/ pubmed/25106547

5. Peric A, Gacesa D. Etiology and pathogenesis of chronic rhinosinusitis. Vojnosanit Pregl 2008; 65(9): 699-702. [PubMed] https://www.ncbi.nlm.nih.gov/pubmed/18814507

6. Ansari NN, Fathali M, Naghdi S, Hasson S. Effect of pulsed ultrasound on chronic rhinosinusitis:A case report.Physiother Theory Pract 2010; 26(8): 558-563.[PubMed] https://www.ncbi. nlm.nih.gov/pubmed/20673076
7. Mittal P, Gupta V, Goswami V, Thakur N, Bansal P. Phytochemical and Pharmacological Potential of Viola odorata. International Journal of Pharmacognosy. Int J Pharmacognosy 2015; 2(5): 215-220.

8. Mittal S. Thin Layer Chromatography and High Pressure Liquid Chromatography Profiling of Plant Extracts of Viola odorataLinn. Int J Pharm Bio Sci 2013 Jan; 4(1): (B) 542-549.

9. Gautam SS, Bithel N, Kumar S, Painuly D, Singh J. A New Derivative of lonone from Aerial Parts of Viola odorata Linn. and Its Antibacterial Role against Respiratory Pathogens.Clinical Phytoscience 2016; 2: 4. DOI 10.1186/s40816-016-0018-3

10. Salve T, Rathod V, Tike SK, Kadam R, Khade R. A Review Article on Banafsha(Viola odarata LINN.). Punarnav 2014; 2(4): 1-8. 
Table 5 Comparison of safety profile in the two groups

\begin{tabular}{|l|l|l|l|l|}
\hline Safety parameter & Test group & Control group & Total & $P$ valuea \\
\hline $\begin{array}{l}|l| \\
\text { Blood urea }(\mathrm{mg} / \mathrm{dL})\end{array}$ & $19.40 \pm 3.64$ & $19.47 \pm 3.60$ & $19.43 \pm 3.56$ & 0.96 \\
\hline Before treatment & $16.73 \pm 3.61$ & $17.67 \pm 3.66$ & $17.20 \pm 3.60$ & 0.488 \\
\hline After treatment & $1.15 \pm 0.08$ & $1.07 \pm 0.12$ & $1.11 \pm 0.11$ & 0.057 \\
\hline Serum creatinine (mg/dL) & $1.00 \pm 0.09$ & $0.96 \pm 0.10$ & $0.98 \pm 0.10$ & 0.262 \\
\hline Before treatment & \multicolumn{3}{|l|}{} \\
\hline After treatment & $23.00 \pm 2.98$ & $23.33 \pm 2.85$ & $23.17 \pm 2.87$ & 0.756 \\
\hline SGOT (IU/L) & $21.07 \pm 2.52$ & $21.20 \pm 3.61$ & $21.13 \pm 3.06$ & 0.907 \\
\hline Before treatment & & & \\
\hline After treatment & $25.40 \pm 3.18$ & $24.73 \pm 2.94$ & $25.07 \pm 3.03$ & 0.556 \\
\hline SGPT (IU/L) & $23.33 \pm 2.53$ & $23.53 \pm 3.48$ & $23.43 \pm 2.99$ & 0.858 \\
\hline Before treatment
\end{tabular}

a Student $t$ test (unpaired).

11. Adamowski W. Viola odorataL. (Violaceae) as a Remnant of Former Cultivation in the Bialowieza Forest Region. Ukr. Botan. Journ. 2012, vol. 69(3): 379-384.

12. Kaloo ZA, Akhtar R, Haq Z, Wafai BA. Effect of growth regulators on the in vitro multiplication of Viola odorata. International Journal of Medicinal Plant Research. 2013; 2(4): 187-189.

13. Ghani HN, Khazayin-ul-adviyah, New Delhi, Ejaz publishing hous, YNM, 397, 398.

14. Anonymous,Standardization of single drugs of Unani Medicine, Part 2, New Delhi, CCRUM, 1992,149-152.

15. Ibn Baitar, Al-JamiulMufridat Al-Adviawa Al-Aghzia (Urdu translation) Vol I, New Delhi, CCRUM Ministry of Health and Family Welfare, YNM, 287-289.

16. Qasemzadeh MJ, Sharifi H, Hamedanian M, Gharehbeglou M Heydari M, Sardari M, et al. The Effect of Viola odorata Flower Syrup on the Cough of Children with Asthma: A DoubleBlind, Randomized Controlled Trial. Journal of Evidence-Based Complementary \& Alternative Medicine 2015; 20(4): 287-291. https://www.ncbi.nlm.nih.gov/pubmed/25954025

17. Ali MY, Qadir MI, Rasool S, Abbas G, Ahmed S, Aslam Z, et al. Effectiveness of Viola odorata Flower Decoction for Tonsillitis and Peritonsillar Abscess. Journal of Rashid Latif Medical College 2013; 2: 51-53.

18. Gillespie MB, Osguthorpe JD. Pharmacologic Management of Chronic Rhinosinusitis, Alone or with Nasal Polyposis. Current Allergy and Asthma Reports 2004; 4: 478-485.https://www. ncbi.nlm.nih.gov/pubmed/15462715

19. Brown C. Chronic rhinosinusitis: 'It's my sinus doc!'Australian Family Physician; May 2008; 37(5): 306.https://www.ncbi.nlm. nih.gov/pubmed/18464958

20. Lal D, Stankiewicz JA. Antifungal Treatment and Chronic Rhinosinusitis. Current Allergy and Asthma Reports 2009; 9: 227-231.

21. Gautam SS, Navneet, Kumar S. The Antibacterial and Phytochemical Aspects of Viola odorata Linn. Extracts Against Respiratory Tract Pathogens. Proc. Natl. Acad. Sci., India, Sect. B Biol. Sci. 2012; 82(4): 567-572.

22. Khan MA, Prakash R, Ali S, Aljarbou A, Khan MA. Comparative Study of Antibacterial Activity and Toxicity of Certain Plants used in Unani Medicine. Advances in Bioresearch 2011; 2(2): 10-13.

23. Hassan F, Naeeml.Biological Activity of Viola odorata Linn against Mycobacterium tuberculosis. Int J Pharm Bio Sci 2014 5(3): 61-69.

24. Singh MP, Singh JSD, Rajesh R. The efficacy of polyherbal formulation of Moringaoleifera, Viola odorata, Allium sativum against microbes- synergistic effect. Indian J.Pharm.Biol.Res. 2015; 3(4): 6-10.

25. Choopani R, Sadr S, Kaveh S, Kaveh N, Dehghan S. Pharmacological treatment of catarrh in Iranian traditional medicine. JTradit and Complement Med 2015; 5: 71-74.https:// www.ncbi.nlm.nih.gov/pubmed/26151014

26. Koochek MH, Pipelzadeh MH, Mardani $\mathrm{H}$. The Effectiveness of Viola odorata in the Prevention and Treatment of FormalinInduced Lung Damage in the Rat. Journal of Herbs, Spices \& Medicinal Plants 2003; 10(2): 95-103.

27. Monadi A, Rezaie A. Evaluation of Sedative and Pre-Anesthetic Effects of Viola odorata Linn. Extract Compared With Diazepam in Rats. Bull. Env. Pharmacol. Life Sci. 2013; 2 (7): 125-131.

28. Vishal A, Parveen K, Pooja S, Kannappan N, Kumar S. Diuretic, Laxative and Toxicity Studies of Viola odorata Aerial Parts. Pharmacologyonline 2009; 1: 739-748.

29. Feyzabadi Z. Jafari F, Kamali SH, Ashayeri H, Aval SB, Esfahani MM, et al. Efficacy of Viola odorata in Treatment of Chronic Insomnia. Iran Red Crescent Med J. 2014; December; 16(12) https://www.ncbi.nlm.nih.gov/pubmed/25763239

30. Takeno S, Hirakawa K, Ishino T. Pathological Mechanisms and Clinical Features of Eosinophilic Chronic Rhinosinusitis in the Japanese Population. Allergology International. 2010; 59: 247256.

31. Sreeparvathi A, Kalyanikuttyamma LK, Kumar M, Sreekumar $\mathrm{N}$, Veerasigamani N. Significance of Blood Eosinophil Count in Patients with Chronic Rhinosinusitis with Nasal Polyposis. J ClinDiagn Res. 2017; 11(2): 08-11. https://www.ncbi.nlm.nih. gov/pmc/articles/PMC5376914/

32. Bachert C, Zhang L, Gevaert P. Current and future treatment options for adult chronic rhinosinusitis: Focus on nasal polyposis. J Allergy Clinlmmunol2015; 136(6): 1431-1440. https://www.ncbi.nlm.nih.gov/pubmed/26654192

33. Dixon AE, Castro M, Cohen RI, Gerald LB, Holbrook JT, Irvin CG, et al. Efficacy of nasal mometasone for the treatment of chronic sinonasal disease in patients with inadequately controlled asthma. J Allergy Clinlmmunol2015; 135(3): 701-709.https:// www.ncbi.nlm.nih.gov/pubmed/25174863

34. Broderick DF. The opacified paranasal sinus: Approach and differential. Applied Radiology 2015; 9-17.

35. Drozdova IL, Bubenchikov RA. Composition and Antiinflammatory Activity of Polysaccharide Complexes Extracted from Sweet Violet and Low Mallow. Pharmaceutical Chemistry Journal 2005; 39(4): 197-200. 